\title{
Candidates for Treatment of Novel Corona virus disease, COVID-19: Current Scenario and Way Forwards
}

\author{
Abu Bashar* \\ MD, Assistant Professor, Community Medicine, IMS, BHU, Varanasi, India
}

Corresponding Author: Abu Bashar, Community Medicine, IMS, BHU, Varanasi, India.

Received Date: December 03, 2020; Accepted Date: December 30, 2020; Published Date; January $12,2021$.

Citation: Abu Bashar, Candidates for Treatment of Novel Corona virus disease, COVID-19: Current Scenario and Way Forwards, J. Clinical Oncology Research and Reports. 2(2). Doi: 10.31579/2693-4787/016

Copyright: () 2020 Abu Bashar, This is an open-access article distributed under the terms of the Creative Commons Attribution License, which permits unrestricted use, distribution, and reproduction in any medium, provided the original author and source are credited

\begin{abstract}
Severe acute respiratory syndrome coronavirus 2 (SARS-CoV-2), the cause of coronavirus disease 2019 (COVID-19), has spread across the globe resulting in a pandemic affecting 215 countries. At the time of this review, COVID-19 has been diagnosed in more than 15,000,000 patients and associated with over 1,00,000 deaths globally (Canters for Disease Control and Prevention, World Health Organization).

In this review, we herein summarize the current evidence as on June 15, 2020 to provide guidance on potential drugs for COVID-19 treatment or prophylaxis, their scientific rationale and their clinical efficacy and safety. New data continue to emerges daily regarding clinical characteristics, treatment options, and outcomes for COVID-19. Optimized supportive care remains the mainstay of therapy, and the clinical efficacy for the potential therapeutic agents is still under investigation.

Key words: SARS-CoV-2; COVID-19; Lopinavir/Ritonavir; Hydroxychloroquine; Remdesivir; Ivermectin; Nitazoxanide
\end{abstract}

\section{Introduction}

Since the first case was reported in December 2019 from Wuhan, China, infection with the severe acute respiratory coronavirus 2 (SARS-CoV-2) has become a worldwide pandemic affecting 215 countries [1, 2]. World Health Organization (WHO) declared the outbreak of SARS-Cov-2 as a Public Health Emergency of International Concern on 30 January 2020 [3]. Covid-19 - the illness caused by SARS-CoV-2 - is overpowering the existing health care systems globally $[4,5]$. The international community has asked for US\$675 million to help protect states with weaker health systems as part of its Strategic Preparedness and Response Plan [3].

The symptoms of SARS-CoV-2 infection vary broadly, from asymptomatic disease to pneumonia and life-threatening complications, including acute respiratory distress syndrome, multisystem organ failure, and ultimately, death [6]. Older patients and those with pre-existing respiratory or cardiovascular conditions appear to be at the greatest risk for severe complications $[7,8]$. Thus far, there are no specific therapeutic agents for coronavirus infections. In the absence of a proven effective treatment, current management consists of supportive care, including invasive and non-invasive oxygen support and treatment with antibiotics $[9,10]$. In addition, many patients have received off-label or compassionate-use therapies, including anti-retrovirals, anti-parasitic agents, anti-inflammatory compounds, and convalescent plasma [11-14]. In this commentary, we aim to assess the potential candidates for treatment and prevention of Covid-19 based on the scientific evidences.

\section{Antiretroviral drugs}

After the emergence of severe acute respiratory syndrome (SARS) in 2003, screening of approved drugs identified lopinavir, a human immunodeficiency virus (HIV) type 1 aspartate protease inhibitor, as having in vitro inhibitory activity against SARS-CoV, the virus that causes SARS in humans [15-17]. Lopinavir, which acts against the viral $3 \mathrm{CL}$ protease, has modest antiviral activity against SARS-CoV-2 in vitro [18]. Ritonavir is combined with lopinavir to increase its plasma half-life through the inhibition of cytochrome P450. An open-label study published in 2004 suggested, by comparison with a historical control group that received only ribavirin, that the addition of lopinavir-ritonavir (400 mg and $100 \mathrm{mg}$, respectively) to ribavirin reduced the risk of adverse clinical outcomes (acute respiratory distress syndrome [ARDS] or death) as well as viral load among patients with SARS[15]. However, the lack of randomization and a contemporary control group and the concomitant use of glucocorticoids and ribavirin in that study made the effect of lopinavir-ritonavir difficult to assess. Similarly, lopinavir has activity, both in vitro [19] and in an animal mode [20], against Middle East respiratory syndrome coronavirus (MERS-CoV), and case reports have suggested that the combination of lopinavir-ritonavir with ribavirin and interferon alfa resulted in virologic clearance and survival [21-23].Chao et. Al [24] conducted a randomized controlled open label trial in hospitalized adult Covid-19 patients to evaluate the efficacy and safety of oral lopinavir-ritonavir for SARS-CoV-2 infection from January 18, 2020, through February 3, 2020 at Jin Yin-Tan Hospital, Wuhan, Hubei Province, China. The researchers concluded that lopinavir-ritonavir treatment did not significantly accelerate clinical improvement, reduce 
mortality, or diminish throat viral RNA detectability in patients with serious Covid-19 [24]. Combining lopinavir-ritonavir with other antiviral agents, as has been previously done in SARS $[15,25]$ and is being studied in MERS-CoV [26], might enhance antiviral effects and improve clinical outcomes but it remains to be determined through further studies.

\section{Nucleoside analogue}

\section{Remdesivir}

Remdesivir is a prodrug of a nucleotide analogue that is intracellularly metabolized to an analogue of adenosine triphosphate that inhibits viral RNA polymerases. Remdesivir has broad-spectrum activity against members of several virus families, including filoviruses (e.g., Ebola) and coronaviruses (e.g., SARS-CoV and MERS-CoV) and has shown prophylactic and therapeutic efficacy in nonclinical models of these coronaviruses [27-30]. In vitro testing has also shown that remdesivir has activity against SARS-CoV-2. Remdesivir appears to have a favourable clinical safety profile $[31,32]$. A recent study by Grein et al., sponsored by Gilead Sciences, on a cohort of patients hospitalized for severe Covid19 and treated with remdesivir on a compassionate-use basis observed clinical improvement in 36 of 53 patients (68\%) [33]. However, interpretation of the results of this study is limited by the small size of the cohort, the relatively short duration of follow-up, potential missing data owing to the nature of the program, the lack of information on 8 of the patients initially treated, and the lack of a randomized control group, the latter preventing from definitive conclusions. However, comparisons with contemporaneous cohorts from the literature, in whom general care is expected to be consistent with that of the study cohort, suggest that remdesivir may have clinical benefit in patients with severe Covid-19. However, measurement of efficacy will require ongoing randomized, placebo-controlled trials of remdesivir therapy and the findings from this study is needed to be confirmed by the ongoing randomized, placebocontrolled trials of remdesivir therapy for Covid-19.

\section{Anti malarials/ Anti-parasitic}

\section{Chloroquine and Hydroxychloroquine}

Chloroquine, an antimalarial drug with anti-inflammatory and immunomodulatory actions, has gained substantial interest as a potential therapeutic choice for the management of COVID 19 [34]. A recent paper reported an inhibitor effect of chloroquine on the growth of SARS-CoV2 in vitro,[30] and an early clinical trial conducted in COVID-19 Chinese patients, showed that chloroquine had a significant effect, both in terms of clinical outcome and viral clearance, when comparing to controls groups[35]. Chinese experts in their consensus report recommended that patients diagnosed as either mild, moderate or severe cases of COVID-19 pneumonia and without contraindications to chloroquine, be treated with $500 \mathrm{mg}$ chloroquine twice a day for ten days [36].

Hydroxychloroquine (an analogue of chloroquine) has been demonstrated to have an anti-SARS-CoV activity in vitro [37]. Hydroxychloroquine clinical safety profile is better than that of chloroquine (during long-term use) and allows higher daily dose [38] and has fewer concerns about drugdrug interactions [39].

In a recent nonrandomized study from France, Gautret and colleagues[40] reported a higher frequency of SARS-CoV-2 clearance from the nasopharynx after 6 days of treatment with HCQ, plus azithromycin (AZM) if deemed necessary, versus an untreated control group (14 of 20 patients [70\%] vs. 2 of 16 patients [13\%]; $<<0.001$ ). The clinical study showed that hydroxychloroquine treatment is significantly associated with viral load reduction/disappearance in COVID-19 patients. As per the researchers, results were promising and open the possibility of an international strategy to fight this emerging viral infection in real-time even if other strategies and research including vaccine development could be also effective, but would take time to develop. Given the urgency of the situation, some limitations of this study was acceptable, including the small sample size, use of an un-validated surrogate end point, and lack of randomization or blinding. However, many methodological flaws which were also noted by others [41] severely affect the validity of the study findings.

Yet, another very small, randomized study from China in patients with mild to moderate COVID-19 found no difference in recovery rates in patients receiving hydroxychloroquine and in patients receiving only standard supportive care[42]. Most recently, a report by Chen et al [43] presented data from a study including 62 patients with non-severe, noncritical COVID-19 who were randomly assigned to receive hydroxychloroquine (200 $\mathrm{mg}$ twice a day for 5 days) or standard treatment. Results showed that duration of fever (2.2 vs 3.2 days) and cough (2.0 vs 3.1 days) was shorter among members of the group receiving hydroxychloroquine, and that more patients receiving hydroxychloroquine had improved findings on chest computed tomographic imaging [43]. It should also be noted that there is concern for QTc prolongation and torsades de pointes even with short-term use of hydroxychloroquine for COVID-19 which may pose particular risk to critically ill persons [44].

The evidence, thus so far, for the use of hydroxychloroquine in the treatment of human infection with SARS-CoV-2 is based on encouraging in vitro data, very small clinical studies, and anecdotal observation. Well performed randomized clinical trials with adequate sample size and validated clinical end points, are required to better understand if hydroxychloroquine has any definitive role in the treatment of COVID19.

\section{Ivermectin}

Ivermectin is an FDA-approved broad spectrum anti-parasitic agent [45] that in recent years, has shown to have anti-viral activity against a broad range of viruses [46-49] in vitro. According to a recent in vivo study [49] by researchers from Monash University, Australia, Ivermectin is an inhibitor of the causative virus (SARS-CoV-2), with a single addition to Vero-hSLAM cells 2 hours post infection with SARS-CoV-2 able to effect $\sim 5000$-fold reduction in viral RNA at 48 hours indicating that ivermectin treatment resulted in the effective loss of essentially all viral material by 48 hours. Ivermectin, therefore, warrants further investigation for possible benefits in humans.

\section{Nitazoxanide}

Nitazoxanide has demonstrated potent in vitro activity against SARS CoV-2, with an EC50 at 48 hours of $2.12 \mu \mathrm{M}$ in Vero E6 cells [30].This potent activity is consistent with EC50 values for nitazoxanide and its active metabolite, tizoxanide, against MERS-CoV in LLC-MK2 cells in which EC50 values of 0.92 and $0.83 \mu \mathrm{M}$, respectively, have been demonstrated [52]. Nitazoxanide displays broad-spectrum in vitro antiviral activity against influenza, respiratory syncytial virus, parainfluenza, rotavirus, and norovirus among others in addition to coronaviruses [52].

Due to its broad-spectrum antiviral activity, nitazoxanide is being investigated for the management of influenza and other acute respiratory infections. Positive results were demonstrated in a phase $2 b / 3$ study for the outpatient management of influenza, in which a dose of $600 \mathrm{mg}$ by mouth BID of nitazoxanide was associated with a $~ 1$-day improvement in time to resolution of symptoms when compared with placebo $(P=.008)$ [53].

Nitazoxanide failed to reduce the duration of hospitalization or the time to symptom alleviation in a phase 2 randomized controlled trial in patients with severe acute respiratory illnesses requiring hospitalization, 
predominantly caused by respiratory viruses [54]. Despite the encouraging in vitro activity of nitazoxanide against SARS-CoV-2, data are currently lacking for its role in the management of COVID-19.

\section{Conclusion}

Suitable management strategies for patients with COVID 19 are a rapidly evolving therapeutic challenge, and the optimal agents to treat or prevent infection or prevent progression to critical illness remain poorly defined. Although results of certain agents listed in this review are encouraging, the evidence remains inconclusive in view of lack of well performed randomized controlled trials (RCTs) to prove their efficacy and safety beyond doubt. Some of the agents reported here are currently undergoing investigation through RCTs and clinical trials which may come with conclusive results in future.

Given that disease progression of COVID 19 can occur rapidly in stable patients and that viral loads are highest early in the course of infection, the rapid initiation of therapy in high-risk populations is rational and must be considered, ideally in the context of a well-controlled, adequately powered trial. Clinicians should also continually monitor and adapt as new literature becomes available in coming days.

\section{References:}

1. Cucinotta D, Vanelli M. WHO declares COVID-19 a pandemic. Acta Biomed 2020; 91:157-160

2. Spinelli A, Pellino G. COVID-19 pandemic: perspectives on an unfolding crisis. Br J Surg 2020 March 19 (Epub ahead of print).

3. World Health Organization. Rolling updates on Corona virus disease Covid19. Available from https://www.who.int/emergencies/diseases/novel-coronavirus2019/events-as-they-happen

4. Fauci AS, Lane HC, Redfield RR. Covid-19 - navigating the uncharted. N Engl J Med 2020; 382:1268-1269.

5. Mahase E, Kmietowicz Z. Covid-19: doctors are told not to perform CPR on patients in cardiac arrest. BMJ 2020;368:m1282-m1282.

6. Rodriguez-Morales AJ, Cardona-Ospina JA, GutiérrezOcampo E, et al. Clinical, laboratory and imaging features of COVID-19: a systematic review and meta-analysis. Travel Med Infect Dis 2020March 13 (Epub ahead of print).

7. Weiss $\mathrm{P}$, Murdoch DR. Clinical course and mortality risk of severe COVID-19. Lancet 2020; 395:1014-1015.

8. Wu C, Chen X, Cai Y, et al. Risk factors associated with acute respiratory distress syndrome and death in patients with coronavirus disease 2019 pneumonia in Wuhan, China. JAMA Intern Med 2020 March 13 (Epub ahead of print).

9. Onder G, Rezza G, Brusaferro S. Case-fatality rate and characteristics of patients dying in relation to COVID-19 in Italy. JAMA 2020 March 23 (Epub ahead of print).

10. Poston JT, Patel BK, Davis AM. Management of critically ill adults with COVID-19. JAMA 2020 March 26 (Epub ahead of print).

11. Cao B, Wang Y, Wen D, et al. A trial of lopinavir-ritonavir in adults hospitalized with severe Covid-19. N Engl J Med.

12. Shen C, Wang Z, Zhao F, et al. Treatment of 5 critically ill patients with COVID-19 with convalescent plasma. JAMA 2020 March 27 (Epee ahead of print).

13. Touret F, de Lamballerie X. Of chloroquine and COVID-19. Antiviral Res 2020 March 5 (Epub ahead of print).

14. Baden LR, Rubin EJ. Covid-19 - the search for effective therapy. N Engl J Med.
15. Chu CM, Cheng VC, Hung IF, et al. Role of lopinavir/ritonavir in the treatment of SARS: initial virological and clinical findings. Thorax 2004; 59:252-256.

16. Chen F, Chan KH, Jiang Y, et al. In vitro susceptibility of 10 clinical isolates of SARS coronavirus to selected antiviral compounds. J Clin Virol 2004; 31:69-75.

17. Wu C-Y, Jan J-T, Ma S-H, et al. Small molecules targeting severe acute respiratory syndrome human coronavirus. Proc Natl Acad Sci U S A 2004; 101:10012-10017.

18. Sheahan TP, Sims AC, Leist SR, et al. Comparative therapeutic efficacy of remdesivir and combination lopinavir, ritonavir, and interferon beta against MERS-CoV. Nat Comm 2020; 11:222222.

19. de Wilde AH, Jochmans D, Posthuma CC, et al. Screening of an FDA-approved compound library identifies four smallmolecule inhibitors of Middle East respiratory syndrome coronavirus replication in cell culture. Antimicrob Agents Chemother 2014; 58:4875-4884.

20. Chan JF-W, Yao Y, Yeung M-L, et al. Treatment with lopinavir/ritonavir or interferon- $\beta 1 \mathrm{~b}$ improves outcome of MERS-CoV infection in a nonhuman primate model of common marmoset. J Infect Dis 2015; 212:1904-1913.

21. Kim UJ, Won E-J, Kee S-J, Jung S-I, Jang H-C. Combination therapy with lopinavir/ritonavir, ribavirin and interferon- $\alpha$ for Middle East respiratory syndrome. Antivir Ther 2016; 21:455459.

22. Spanakis N, Tsiodras S, Haagmans BL, et al. Virological and serological analysis of a recent Middle East respiratory syndrome coronavirus infection case on a triple combination antiviral regimen. Int J Antimicrob Agents 2014; 44:528-532.

23. Min C-K, Cheon S, Ha N-Y, et al. Comparative and kinetic analysis of viral shedding and immunological responses in MERS patients representing a broad spectrum of disease severity. Sci Rep 2016; 6:25359-25359.

24. Cao B, Wang Y, Wen D, et al. A trial of lopinavir-ritonavir in adults hospitalized with severe Covid-19. N Engl J Med.

25. Chan KS, Lai ST, Chu CM, et al. Treatment of severe acute respiratory syndrome with lopinavir/ritonavir: a multicentre retrospective matched cohort study. Hong Kong Med J 2003; 9:399-406.

26. Arabi YM, Alothman A, Balkhy HH, et al. Treatment of Middle East Respiratory Syndrome with a combination of lopinavirritonavir and interferon- $\beta 1 \mathrm{~b}$ (MIRACLE trial): study protocol for a randomized controlled trial. Trials 2018; 19:81-81.

27. de Wit E, Feldmann F, Cronin J, et al. Prophylactic and therapeutic remdesivir (GS-5734) treatment in the rhesus macaque model of MERS-CoV infection. Proc Natl Acad Sci U S A 2020; 117:6771-6776.

28. Sheahan TP, Sims AC, Graham RL, et al. Broad-spectrum antiviral GS-5734 inhibits both epidemic and zoonotic coronaviruses. Sci Transl Med 2017;9(396): eaal3653eaal3653.

29. Sheahan TP, Sims AC, Leist SR, et al. Comparative therapeutic efficacy of remdesivir and combination lopinavir, ritonavir, and interferon beta against MERS-CoV. Nat Commun 2020; 11:222-222

30. Wang M, Cao R, Zhang L, et al. Remdesivir and chloroquine effectively inhibit the recently emerged novel coronavirus (2019-nCoV) in vitro. Cell Res 2020; 30:269-271.

31. Mulangu S, Dodd LE, Davey RT Jr, et al. A randomized, controlled trial of Ebola virus disease therapeutics. N Engl J Med 2019; 381:2293-2303.

32. European Medicines Agency. Summary on compassionate use: Remdesivir Gilead. April 3, 2020 
(https://www.ema.europa.eu/en/documents/other/summarycompassionate-use-remdesivir-gilead_en.pdf. opens in new tab).

33. Grein J, Ohmagari N, Shin D, et. al. Compassionate Use of Remdesivir for Patients with Severe Covid-19. New England Journal of Medicine. April, 2020.

34. P. Colson, J.-M. Rolain, D. Raoult. Chloroquine for the 2019 novel coronavirus SARS-CoV-2 Int. J. Antimicrob. Agents (2020)

35. Gao J, Tian Z, Yang X. Breakthrough: Chloroquine phosphate has shown apparent efficacy in treatment of COVID-19 associated pneumonia in clinical studies. Biosci Trends. 2020 Feb 19 [Epub ahead of print]

36. Multicenter collaboration group of Department of Science and Technology of Guangdong Province and Health Commission of Guangdong Province for chloroquine in the treatment of novel coronavirus pneumonia. Expert consensus on chloroquine phosphate for the treatment of novel coronavirus pneumonia] Zhonghua Jie He He Hu Xi Za Zhi. 2020 Mar 12;43(3):185188.

37. Biot C, Daher W, Chavain N, Fandeur T, Khalife J, Dive D. Design and synthesis of hydroxyferroquine derivatives with antimalarial and antiviral activities. J Med Chem. 2006; 49:2845-2849.

38. Marmor MF, Kellner U, Lai TY, Melles RB. Mieler WF; American Academy of Ophthalmology. Recommendations on Screening for Chloroquine and Hydroxychloroquine Retinopathy (2016 Revision) Ophthalmology. 2016 Jun;123;(6):1386-1394

39. Yao X, Ye F, Zhang M, Cui C, Huang B, Niu P. In Vitro Antiviral Activity and Projection of Optimized Dosing Design of Hydroxychloroquine for the Treatment of Severe Acute Respiratory Syndrome Coronavirus 2 (SARS-CoV-2) Clin Infect Dis. 2020 Mar 9 pii: ciaa237.

40. Gautret P, Lagier JC, Parola P, et al. Hydroxychloroquine and azithromycin as a treatment of COVID-19: results of an openlabel non-randomized clinical trial. Int J Antimicrob Agents. 2020:105949.

41. Dahly D, Gates S, Morris T. Statistical review of hydroxychloroquine and azithromycin as a treatment of COVID-19: results of an open-label nonrandomized clinical trial. Preprint. Posted online 23 March 2020. Zenodo.

42. Chen J, Liu D, Liu L, et al. A pilot study of hydroxychloroquine in treatment of patients with common coronavirus disease-19 (COVID-19). Journal of Zhejiang University (Medical Sciences). 2020;49(1).0-0
43. Chen Z, Hu J, Zhang Z, et al. Efficacy of hydroxychloroquine in patients with COVID-19: results of a randomized clinical trial [published online March 31, 2020]. MedRxiv.

44. Giudicessi JR, Noseworthy P, Friedman PA, et al. Urgent guidance for navigating and circumventing the QTc prolonging and torsadogenic potential of possible pharmacotherapies for COVID-19 [published online March 25, 2020]. Mayo Clin Proc.

45. Gonzalez Canga A. The pharmacokinetics and interactions of ivermectin in humans--a mini-review. AAPS J. 2008;10(1):4246.

46. Gotz V. Influenza A viruses escape from $\mathrm{MxA}$ restriction at the expense of efficient nuclear vRNP import. Sci Rep. 2016; 6:23138.

47. Lundberg L. Nuclear import and export inhibitors alter capsid protein distribution in mammalian cells and reduce Venezuelan Equine Encephalitis Virus replication. Antiviral Res. 2013;100(3):662-672.

48. Tay M.Y. Nuclear localization of dengue virus (DENV) 1-4 non-structural protein 5; protection against all 4 DENV serotypes by the inhibitor Ivermectin. Antiviral Res. 2013;99(3):301-306.

49. Wagstaff K.M. Ivermectin is a specific inhibitor of importin alpha/beta-mediated nuclear import able to inhibit replication of HIV-1 and dengue virus. The Biochemical journal. 2012;443(3):851-856.

50. Caly, L., Druce, J.D., Catton, M.G., Jans, D.A., Wagstaff, K.M., The FDA-approved Drug Ivermectin inhibits the replication of SARS-CoV-2 in vitro, Antiviral Research.

51. Rossignol JF. Nitazoxanide, a new drug candidate for the treatment of Middle East respiratory syndrome coronavirus. J Infect Public Health 2016; 9:227-30.

52. Haffizulla J, Hartman A, Hoppers M, et al. Effect of nitazoxanide in adults and adolescents with acute uncomplicated influenza: a double-blind, randomised, placebocontrolled, phase 2b/3 trial. Lancet Infect Dis 2014; 14:609-18.

53. Gamiño-Arroyo AE, Guerrero ML, McCarthy S, et al. Efficacy and safety of nitazoxanide in addition to standard of care for the treatment of severe acute respiratory illness. Clin Infect Dis 2019; 69:1903-11. 